UDC: 821.134.2.09-31 Montalbán M. V. DOI: https://doi.org/10.18485/beoiber.2017.1.8

\author{
Sergio García García ${ }^{1}$ \\ Universidad Autónoma de Madrid \\ España
}

\title{
CUESTIÓN DE TATUAJES: LA INFLUENCIA DE LA COPLA EN EL PRIMER CASO DE PEPE CARVALHO²
}

\begin{abstract}
Resumen
Aunque la figura de Pepe Carvalho, no como detective privado sino como agente de la CIA, aparece por primera vez en Yo maté a Kennedy (1972), no es hasta 1974 cuando Manuel Vázquez Montalbán pone a su personaje al frente de su primer caso, el cual se narra en la novela Tatuaje. Dicha novela comparte el nombre de una conocida copla de posguerra interpretada por Conchita Piquer, canción que, además de ser uno de los leitmotiv de la producción literaria y ensayística del escritor barcelonés, desempeña un papel fundamental dentro de la opera prima policíaca de Vázquez Montalbán. Este estudio, pues, tiene como objetivo principal situar la presencia de la canción Tatuaje dentro de la novela homónima, y definir su función y su significado en la resolución del crimen. Asimismo, este análisis se complementa con una comparación de la novela montalbaniana con el relato Tres ratones ciegos (1950), de Agatha Christie, para determinar una posible fuente original del empleo de la canción en la construcción de la novela negra, y con otra novela del barcelonés, La Rosa de Alejandría (1984), también perteneciente a la serie Carvalho, y cuyo título, como el de Tatuaje, hace referencia a una canción popular.

Palabras clave: Conchita Piquer, Manuel Vázquez Montalbán, novela policiaca, Pepe Carvalho, Tatuaje.

\section{TATTOO MATTERS: THE INFLUENCE OF THE COPLA IN PEPE CARVALO'S FIRST CASE}

Abstract

Although the figure of Pepe Carvalho, not as a private investigator, but as a CIA operative, appears for the first time in Yo maté a Kennedy (1972), it is not until 1974 that Manuel Vázquez Montalbán places him in charge of his first case, which is narrated in the novel Tatuaje. The above-mentioned novel shares its

\footnotetext{
1 sergio.garciag@uam.es

2 Este estudio se ha llevado a cabo en el marco del «Programa propio de ayudas para Formación del Personal Investigador. FPI-UAM" de la Universidad Autónoma de Madrid, convocatoria de 2015, dentro del proyecto de tesis doctoral “La poesía de Manuel Vázquez Montalbán: 1963-2003”.
} 
name with a popular postwar Spanish copla performed by Conchita Piquer, a music theme that, apart from being one of the leitmotifs of the writer's literary and essayistic production plays an essential role within Montalban's whodunit debut feature. The main purpose of this study is to locate Conchita Piquer's theme, Tatuaje, in the homonymous novel, and to establish its role and significance in solving the crime represented in the text. Furthermore, this analysis is complemented by a comparison between Tatuaje and Three Blind Mice and Other Stories (1950) by Agatha Christie - in order to determine a potential original source of the use of the song in the construction of the thriller - and also with another novel of the Barcelonian, La Rosa de Alejandría (1984), also belonging to the Carvalho series, and whose title, like Tatuaje, refers to a folk song.

Key words: Conchita Piquer, Manuel Vázquez Montalbán, detective novel, Pepe Carvalho, Tatuaje.

\section{Introducción: Conchita Piquer en la obra de Manuel Vázquez Montalbán}

En 1974, dos años después de la aparición de Yo maté a Kennedy. Impresiones, observaciones y memorias de un guardaespaldas, Manuel Vázquez Montalbán publicó la novela Tatuaje en una de las colecciones de José Batlló con una tirada inicial de 1.500 ejemplares (Fernández Colmeiro 2013: 62), obra para cuyo protagonista el barcelonés recuperó la figura que estaba detrás de la voz narrativa de Yo maté a Kennedy, y que resultó ser, como se averigua al final de la novela, Pepe Carvalho. Para Vázquez Montalbán ese tal Carvalho "era un personaje de novela negra, aunque no estuviera como tal en Yo maté a Kennedy" (Fernández Colmeiro 2003: 63), y gracias a ello a la narrativa montalbaniana se le fueron añadiendo una serie de novelas de corte policiaco protagonizadas por este detective gallego. Pero el punto de partida de esta narrativa detectivesca, la ya mencionada obra Tatuaje -novela que el propio detective privado utiliza para encender una de sus diarias chimeneas en Federico III de Castilla y León ${ }^{3}-$, así como del resto de casos de Carvalho, no responde al descubrimiento de la naturaleza del personaje, sino a "una apuesta etílica" que el propio autor llevó a cabo con algunos de sus amigos. Así recuerda Vázquez Montalbán aquella anécdota:

Tatuaje fue una broma, una apuesta etílica después de una cena con el editor de casi todos mis libros de poemas, Pepe Batlló, y otros más. Desde hace muchos años lanzo, de vez en cuando, una boutade diciendo que los valores literarios son convencionales, que por qué es mejor Unamuno que Mika Waltari o por qué dice la gente que Hemingway es mejor que Gore Vidal. Sé que es una exageración y lo hago para irritar y provocar; pero de pronto dije «bueno, pues muy bien, poneros todos a hacer novela policíaca y dejaros de esas novelas en las que vuestros personajes son hasta incapaces de subir una escalera o de abrir una ventana" y me

3 "Carvalho se quita los zapatos con los pies y se deja caer en el sofá de su casa. Se estremece. Siente frío. Se levanta. Busca un libro en la biblioteca. Escoge Tatuaje de Manuel Vázquez Montalbán y lo utiliza como papel base para prender fuego a una fogata que se convierte en el único punto de luz y calor de la estancia" (Vázquez Montalbán 1989: 37).

BEOIBERÍsTICA Vol. I / Número 1 (2017) | 117-132 
dijeron que por qué no hacía yo una novela policíaca; "yo hago una novela policíaca en quince días" dije; me encerré quince días, escribí Tatuaje-se nota que está escrita en quince días - y así empezó el asunto. Al acabarla me quedé tan contento del resultado, reconociendo todas las limitaciones, que programé una serie, y presenté el proyecto a un editor: "Quiero escribir unas diez novelas policíacas, tengo los argumentos desarrollados, más o menos van a ir por aquí, y se van a parecer a ésta por voy a cambiar cosas." Se lo enseñé a Lara y éste me dijo que me olvidara, que eso no iba a tener ningún éxito (Fernández Colmeiro 2003: 63).

Con Tatuaje, entonces, se inaugura el género policiaco en la obra literaria de Vázquez Montalbán; lo que comenzó siendo un pique entre amigos durante una sobremesa, terminó por ser la faceta más conocida del autor barcelonés. Aunque ya en Yo maté a Kennedy la figura de Carvalho poesía una notable relevancia, aún no se puede considerar a esta obra como el primer caso del detective, pues esta se enmarca dentro del periodo al que Georges Tyras ha denominado "escritura subnormal" (2007: 105), donde comparte, no solo significado, sino también forma con otros textos como Manifiesto subnormal (1970), Happy End (1974) o Cuestiones marxistas (1974), entre otros. La publicación de Tatuaje supone el fin de la literatura subnormal, así como el inicio, además del arrumbamiento de la novela negra en la producción del barcelonés, de una narrativa realista (Balibrea Enríquez 1998: 565; Stenzel 1994: 256), aunque, como un caso aislado, Carvalho vuelve a protagonizar un relato de corte subnormal en Sabotaje olímpico (1993). Por lo tanto, Tatuaje equivaldría, más que a la primera novela de Pepe Carvalho -este papel lo ocuparía Yo maté a Kennedy, texto que, al margen de su filiación con la escritura subnormal, se podría considerar como la prehistoria literaria de Carvalho, pues parte de su periodo como agente de la CIA y su posterior salida de la agencia secreta se narran en dicho texto-, al primer caso de Pepe Carvalho.

Pero Vázquez Montalbán no rompió por completo con su literatura anterior al escribir y publicar Tatuaje: mantuvo la presencia de un elemento fundamental en su obra poética, especialmente en sus dos primeros poemarios, Una educación sentimental (1967, 1970) y Movimientos sin éxito (1969), y de su obra ensayística; el elemento en cuestión es la copla. Para el barcelonés, este tipo de canción fue el mejor sustitutivo para los colectivos más desfavorecidos de la posguerra de toda aquella literatura culta a la que no tuvieron acceso, e incluso asegura que fueron mucho más útiles aquellos "dos minutos, tres, de historias ensimismadas y a veces perfectas" que aquella literatura de la que carecían (Vázquez Montalbán 2000a: XLIII). El título de la novela alude directamente a la canción Tatuaje, compuesta por Rafael de León, Xandro Valerio y Manuel Quiroga, e interpretada en los años cuarenta por Conchita Piquer. El paratexto con el que se inicia la novela confirma esta relación entre la novela y la canción, cuyo significado se analizará a lo largo de las siguientes páginas; se trata de un fragmento de la letra en el cual se 
describe al marinero con el que la voz narrativa mantuvo una fugaz relación amorosa (Vázquez Montalbán 1982: 5):

Era hermoso y rubio como la cerveza

el pecho tatuado con un corazón

en su voz amarga había la tristeza

doliente y cansada del acordeón. ${ }^{4}$

Vázquez Montalbán sentía una auténtica predilección por esta canción, cuya letra, según su propia interpretación, contiene un mensaje de protesta "de las mujeres españolas a la perpetua espera de sus maridos condenados por la historia. Unos maridos a los que podrían encontrar una noche ahogados en el puerto" (Tyras 2003: 63). Por ello, estas mujeres, esposas, abuelas, madres e hijas de los vencidos cantaban dichas canciones a través de las ventanas abiertas de sus casas (Vázquez Montalbán 2003: 38), clara representación de la mujer ventanera, es decir, de aquellas “mujeres silenciadas y resignadas por la mala situación vital que les ofrecían los años de la posguerra, debido a su adscripción al bando [...] de los perdedores de la guerra, el bando de los padres del poeta" (García García 2016: 62), como expresa el barcelonés en los primeros versos de "Conchita Piquer", poema incluido en Una educación sentimental (Vázquez Montalbán 2000b: 44):
Algo ofendidas, humilladas sobre todo, dejaban en el marco de sus ventanas las nuevas canciones de Conchita Piquer: él llegó en un barco de nombre extranjero, le encontré en el puerto al anochecer (Vázquez Montalbán 2000b: 44).

La alusión intertextual de la letra de Tatuaje en uno de los primeros poemas escritos por el barcelonés, además de ser un excelente ejemplo de “la reutilización de los elementos de la cultura popular como forma de resistencia" (Fernández Colmeiro 2013: 32), inicia un camino de referencias recurrentes a dicha canción -entre las cuales se haya la novela Tatuaje, que en su conjunto es un claro homenaje a la composición de León, Valerio y Quiroga-, que constituirá a este pequeño engranaje de la educación sentimental del autor como uno de los elementos constantes de su ideario literario. Tanto en su producción poética como en la prosaica, Vázquez Montalbán lleva a cabo la inclusión de fragmentos de la letra, a modo de intertexto exoliterario ${ }^{5}$, o de menciones a alguna parte

\footnotetext{
${ }^{4}$ La letra completa de Tatuaje está incluida al final de este estudio a modo de anejo.

5 Se entiende por intertextualidad exoliteraria aquella que se produce cuando "en el texto literario pueden funcionar como intertextos subtextos procedentes de textos ajenos a la literatura, como plegarias 
de su contenido en sus propios textos, lo cual, como establece José Fernández Colmeiro, "proclama abiertamente la naturaleza de construcción ficcional de todo el ciclo narrativo" montalbaniano (2014: 149); por ejemplo, en el poema "Correo sentimental. Respuesta a Enide", incluido en Movimientos sin éxito, poemario que el barcelonés escribió junto con Una educación sentimental en la cárcel de Lérida entre 1962 y 1963, se aprecia la imagen del ese barco, o buque -como se verá más adelante, Vázquez Montalbán suele alternar estos dos términos cuando hace alguna referencia a esta parte de la canción-, de nombre extranjero que llegó a un puerto cualquiera cuando la noche cierra el día:

descendían hacia el puerto

$$
\text { y las gentes }
$$

-se esperaba,

la llegada de un buque de nombre extranjero

que nunca atracó en el puerto al anochecer

[...]

pero en el puerto

nunca llegará -nunca llegaría- el buque

de nombre extranjero y los desencantos conducen

a la evidencia de que ningún buque llega para nadie

(Vázquez Montalbán 2000b: 151 y 152).

También en dos obras pertenecientes a la literatura subnormal montalbaniana encontramos referencias a la canción de la Piquer: primero, en la comedia musical Guillermotta en el país de las Guillerminas (1973), donde en una canción interpretada por la protagonista se advierte la imagen del marino extranjero y tatuado:

Llevaba en la mano una flor malva

un tatuaje en la piel de barco hundido

de su mano me fui la calle arriba

mi patria fue un jergón de lona y sal

era extranjero

más extranjero que la muerte

era marinero

más marinero que la suerte

amo a los extranjeros porque no les entiendo

hay palabras que matan y otras que duermen

marchó una mañana sin decir nada

religiosas, canciones de moda, anuncios publicitarios, prospectos médicos, recetarios de cocina, prensa escrita, ensayos y tratados técnicos y científicos, etc." (Martínez Fernández 2001: 178). 
tenía noche en el pelo y en la mirada

(Vázquez Montalbán 2005: 134 y 135),

y, segundo, la ya citada Cuestiones marxistas, donde la imagen del marinero extranjero aparece de nuevo: “Hermosea tus actos y no llegarás a vieja. Cada cual es dueño de su propia estética. Yo me he forjado un amor imposible con un marineo extranjero. Los extranjeros huelen distinto" (Vázquez Montalbán 2005: 331). Pero la obra que contiene más intertextos extraídos de la canción es, como se ha venido anunciando, la novela Tatuaje.

\section{La copla como clave de bóveda del primer caso carvalhiano}

Gracias al paratexto inicial con el que se abre la novela ("Era hermoso y rubio como la cerveza / el pecho tatuado con un corazón...") se descubre el origen del título de esta, la canción homónima de la Piquer, y se sobreentiende que dicha copla va a desempeñar un papel más o menos relevante en la trama narrada. Tras las primeras páginas, la alusión a la canción adquiere una primera función, que se convertirá en el principal leitmotiv de la novela: en una playa cercana a Barcelona aparece el cadáver de un hombre, "joven y rubio, tostado por el sol" (9) ${ }^{6}$ y con un tatuaje a la espalda, cuyo rostro había sido devorado por los peces; ante la dificultad de conseguir la identidad del muerto, quien la final termina por llamarse Julio Chesma, Vázquez Montalbán se sirve de Tatuaje para hacer frente al "enigma de la identidad" (Balibrea Enríquez 1998: 567) del hombre alto, rubio y tatuado que se le presenta a Carvalho -quien "después de nueve años con la CIA, [...] ha decidido a comenzar a trabajar por libre" $y$, debido a su falta de ahorros y a su rechazo al cuerpo de policía, inicia el oficio de detective privado (Malverde 2010: 255), aunque aún le atraía la idea de recuperar su carrera universitaria, como cuenta él mismo en Las cenizas de Laura (Vázquez Montalbán 1990: 14)-, y casi todas las veces que se refiere al desaparecido lo hace aludiendo a las características del marineo extranjero: "alto y rubio como la cerveza" " -es curioso que este personaje de Tatuaje es el único de toda la canción nacional que no es moreno (Cruz Casado 2010: 137)-; la primera función, por tanto, del empleo de la letra de la canción de León,

${ }^{6}$ De ahora en adelante, en las citas directas de Tatuaje se señalará solo la página, pues todas ellas provienen de la misma edición de la novela ya mencionada.

7 Resulta conveniente señalar que en la versión más conocida de Tatuaje-véase el anexo a este estudio- el adjetivo alto se sustituye por hermoso, como se aprecia en la cita que abre la novela, pero Vázquez Montalbán en todas las referencias a este verso dentro de la obra se decanta por alto. La aparición de ambos adjetivos en la novela puede dar pie a cierta confusión y a pensar que su autor no revisó el texto antes de su publicación; sea lo que fuere, es preciso recordar, como se mencionó al principio de este estudio, que Vázquez Montalbán escribió Tatuaje en dos semanas y que, como él mismo asegura, "se nota que está escrita en quince días" (Fernández Colmeiro 2003: 63).

BEOIBERÍSTICA Vol. I / Número 1 (2017) | 117-132 
Valerio y Quiroga en la novela es la de describir físicamente al misterioso cadáver, y esta alusión, como se ha señalado anteriormente, se convierte en un leitmotiv a lo largo de todo este caso de Carvalho, pues en un total de diez ocasiones se repite esta caracterización, seis de ellos de modo explícito, es decir, entrecomillado, y cuatro, implícito: “Imaginaba el cuerpo de un joven y rubio, “...alto y rubio como la cerveza”, decía la canción” (26), "En el centro de su imaginación aparecía una y otra vez el cuerpo sin rostro de aquel hombre "alto y rubio como la cerveza" (62-63), "Sin duda, en algún lugar que Carvalho desconocía, una mujer, la protagonista de la canción, podía revelarle todos o casi todos los misterios del "hombre alto y rubio como la cerveza"" (64), "Y luego porque Amsterdam era una de las ciudades del mundo que más le habían calado e intuía que el hombre alto y rubio como la cerveza no encajaba totalmente con el modelo del obrero español anclado en la Philips de La Haya" (65), "Ya podía volver a España con el simple nombre del ahogado, pero se había establecido una relación de dependencia con el joven alto y rubio como la cerveza" (95), "Pero en el caso del joven alto y rubio como la cerveza había variantes notables y agradecidas" (96), "Y no pudo hacerlo solo. ¿Cómo iba a poder él solo con el hombre alto y rubio como la cerveza?" (237), así como el siguiente paisaje, donde se cita directamente la letra de la canción:

Y recordaba aquella canción recantada sobre todo por mujeres de la edad que ahora tenía Queta:

"Él llegó en un barco de nombre extranjero

le encontró en el puerto un anochecer..."

Era el amor con un extraño "rubio y alto como la cerveza", "el pecho tatuado con un corazón” (222-223).

Pero la identificación del fallecido Julio Chesma con el marinero de Tatuaje también posee su propio origen en el caso: es Bromuro, el limpiabotas, uno de los principales secundarios de la serie Carvalho, quien relaciona el cadáver encontrado en la playa catalana con el extranjero de la canción, pero a partir de otra parte de la letra. Este pasaje en cuestión es el siguiente:

- Ha aparecido muerto un hombre en una playa. No tenía cara. Se la habían comido los peces y llevaba un tatuaje en la espalda: He nacido para revolucionar el infierno.

-Los hay echaos palante.

-Qué le vamos a hacer.

- ¿En su voz amarga había la tristeza doliente y cansada del acordeón?

-¿De qué coño hablas?

Los ojos acuosos del limpiabotas se perdieron aún más en el complejo de arrugas ennegrecidas que configuraban un rostro a medias ocupado por las arrugas 
y a medias por varices bermejas. Sin duda se estaba riendo, o así al menos creyó Carvalho poder interpretar la conmoción sísmica de las arrugas.

-Es una vieja canción. Se llamaba "Tatuaje" y la cantaba Conchita Piquer.

Carvalho recordó de pronto la canción. La tatareó, primero vacilando, después ya más seguro, con la ayuda de Bromuro. El limpiabotas la cantaba aflamencada y la canción era una tonadilla. Pero Carvalho le dejó cantar y, cuando hubo terminado, se agachó para examinar la marcha del trabajo (18-19).

Gracias al comentario de Bromuro, Carvalho, consciente ahora de la canción y su contenido, entabla la relación del cadáver con el hombre "alto y rubio como la cerveza". $Y$ es en este momento cuando la copla de la Piquer empieza a desempeñar una segunda función dentro de la trama, función que se podría denominar como la principal: añadir una pista más al caso, gracias a la cual Carvalho podrá descubrir no solo quién es el muerto, sino quién lo ha asesinado:

La canción de la que le había hablado el Bromuro le vino de pronto a la memoria, aunque de manera confusa:

“Él llegó en un barco

de nombre extranjero

le encontré en el puerto al anochecer

en su voz amarga había la tristeza

doliente y cansada del acordeón..."

Más o menos así. En otro momento la canción decía:

"Era alto y rubio como la cerveza

y el pecho tatuado con un corazón..."

La canta una mujer que quedó prendada del hermoso extranjero. Del hermoso marino que pasó una noche, sólo una noche, por su vida. ¿Existía esa mujer en el caso del hombre tatuado que estaba buscando? El personaje tenía la dosis de misterio necesaria para que una mujer quedara enganchada en él como los pájaros en el ligue de las ramas (63).

Desde este momento, Vázquez Montalbán, en palabras de María Paz Balibrea, "altera radicalmente lo que en origen se había creado como una fantasía romántica pensada para la identificación de un público femenino popular de postguerra" (1998: 576) y lo convierte, dentro de la novela, en un hecho completamente acaecido en la España todavía franquista. El mito popular pasa a formar parte de la realidad. La recreación mental de Tatuaje por parte del detective en numerosos pasajes, como en el anteriormente citado, le sirve para situar en primera línea de su investigación un nuevo 
sospechoso, en este caso una "mujer que espera sobre cansados mostradores el retorno del joven marino tatuado en el pecho con un corazón" (172):

“Y a los marineros pregunto por él

y nadie me dice si está vivo o muerto

yo sigo en mi duda buscándolo fiel..."

Ante una copa de aguardiente, sobre el cansado mostrador, la mujer de la canción seguía la búsqueda obstinada del hombre que había llegado en un buque de nombre extranjero, con el pecho tatuado sobre el corazón. Carvalho estaba convencido de que aquella mujer existía en el caso presente. En algún lugar, todavía no sabía dónde, una mujer conservaba en su piel las mejores huellas del ahogado ${ }^{8}(96)$.

Y en efecto, la mujer de la canción aparece en la vida real, y resulta ser además la asesina del hombre "alto y rubio como la cerveza": se trata de la amante del cliente de Carvalho, el señor Ramón, de nombre Queta, quien le es a su vez infiel con Julio Chesma y a quien asesina destrozándole la cara con una estatuilla de bronce, instada por el señor Ramón. Volviendo a la afirmación expuesta en el párrafo anterior, el mito popular, pues, se convierte en una realidad clara y concreta.

\section{Justificación y empleo de la copla en otra obra de Vázquez Montalbán: La Rosa de Alejandría}

La famosa copla interpretada por Conchita Piquer "provee el título, el argumento y el tema central" de la primera entrega de la serie Carvalho, como establece Chung-Ying Yang (2005-2006: 431); si no fuera por la jocosa comparación realizada por Bromuro entre la aparición del cadáver con la canción, el detective gallego no hubiera descubierto la clave principal de este crimen pasional. Además, el hecho de que toda la novela gire en torno a esta copla sirve, según Fernández Colmeiro, como un "homenaje privado a una canción extraordinaria de su repertorio sentimental" que realiza Vázquez Montalbán y, asimismo, como "gesto irónico y paródico de las novelas policíacas de la escuela británica de Agatha Christie que sostienen el proceso investigativo sobre los versos de una canción o rima infantil” (2005: 91). Esta segunda hipótesis propuesta por Fernández Colmeiro no debe pasar desapercibida, pues es cierto que algunos casos de Carvalho tuvieron una reconocida influencia de la escritora inglesa; recuérdese los dos relatos carvalhianos, El caso de la abuelita fusilada y El cofre de las tres joyas, recogidos bajo el título Puzzles (Dos homenajes a Agatha Christie), donde, en la segunda obra, parodia de la

${ }^{8}$ Clara referencia a la última estrofa de la canción, con la cual se cierra la novela: “Mira su nombre de extranjero / escrito aquí sobre mi piel, / si te lo encuentras marinero / dile que yo muero por él». 
investigación del asesinato de una mujer rica perpetrado por su mayordomo, el barcelonés declara que "vivir una novela policiaca al estilo Agatha Christie era una tentación para Pepe Carvalho, tan ubicado en la novela negra" (Vázquez Montalbán 1994: 182), así como el relato, fuera de la órbita carvalhiana, El alevoso asesinato de Agatha Christie, recogido en Pigmalión y otros relatos (1987), donde Vázquez Montalbán recrea la muerte de la autora perpetrada por Hércules Poirot, su más conocido personaje. Si se busca un título de Christie con esa característica propuesta por Fernández Colmeiro, como bien podría ser el relato Tres ratones ciegos, incluido en la obra Tres ratones ciegos y otros relatos (1950), y se compara con la novela Tatuaje, las similitudes no son pocas: el relato de Christie también toma el título de una canción, en este caso de una canción infantil inglesa llamada Tres ratones ciegos (Three blind mice), cuya letra también se cita al comienzo del relato; las alusiones a dicha letra son constantes en todo el relato, y el contenido de la canción desvela una pista importante para la resolución del caso (el asesinato de la Mrs. Lyon). Adviértase la relación que guarda el siguiente pasaje del relato de Christie con aquel de Tatuaje en el que Carvalho intuye la presencia de una mujer en la trama -en ambos casos el recuerdo de la letra ayuda al descubrimiento de la pista-:

- Hay algo más que todavía no nos ha dicho, ino es así, sargento?intervino Molly.

-Sí, señora. En la misma página habían escrito: "Tres ratones ciegos". Enganchada a las prendas de la mujer asesinada encontraron una nota que decía: "Este es el primero" $y$, debajo, el dibujo de tres ratones y unas notas musicales que correspondían a la canción que lleva ese nombre:

Molly canturreó:

Tres ratones ciegos.

Tres ratones ciegos.

Mira cómo corren.

Mira cómo corren.

Corren tras la mujer del granjero.

Les...

Se interrumpió.

-Oh, es horrible, horrible. Fueron tres niños, iverdad?

-Sí, Mrs. Davis. Uno de quince años, una niña de catorce y otro niño de doce que murió (Christie 2014: 55-56).

El contenido de la canción descubre al lector que el asesino de Mrs. Lyon, a quien se identifica a lo largo de todo el relato con la canción Tres ratones ciegos, pues siempre que aparece en escena la tatarea, y quien al final resulta ser el sargento Trotter, todavía va a asesinar a dos personas más para completar su venganza personal (Trotter, cuyo verdadero nombre es George, desea vengar a él y a sus hermanos, los "tres ratones ciegos"); gracias a este descubrimiento, el inspector Tanner de Scotland Yard, bajo la 
apariencia de Metcalf, uno de los huéspedes de Molly, consigue salvar a esta última de ser asesinada, pues iba a ser la última víctima del sargento Trotter. Vázquez Montalbán bien pudo recibir algún tipo de influencia de la obra de Christie, como demuestran las líneas anteriores, como la recibió de Raymond Chandler y de otros tantos precursores de la novela negra tras haber agotado "la fase de los experimentos con formas de escritura subversivos y antitradicionales", es decir, su etapa subnormal, como asegura Hartmut Stenzel (1994: 257).

Pero antes de concluir, es preciso dedicar unas pocas líneas a La Rosa de Alejandría (1984), el sexto caso de Pepe Carvalho, cuyo título también hace referencia al de una canción, de una canción popular esta vez: “Eres como la rosa de Alejandría, / colorada de noche blanca de día" (Vázquez Montalbán 1984: 5). Con estos versos, al igual que sucedía en Tatuaje, Vázquez Montalbán anuncia la procedencia del título y, con ello, da a entender al lector que la canción La Rosa de Alejandría va a desempeñar algún tipo de papel dentro de la nueva trama de Carvalho, y, en efecto, lo tiene, pues es el nombre del barco en el que trabaja Ginés Larios Pérez, el asesino de Encarna, cuya macabra muerte (el cadáver apareció descuartizado) se encarga de investigar Carvalho. En un momento de la novela, el capitán de La Rosa de Alejandría, Luis Tourón, les explica a Ginés y al resto de sus hombres el significado del nombre del barco en el que navegan:

\begin{abstract}
-Ah, La Rosa de Alejandría, qué bonito nombre para un barco. Tuve la ocasión de preguntarles a los armadores el porqué de este nombre y fueron estrictamente sinceros, sí, señor, estrictamente sinceros. Porque uno quería llamarlo Rosa en honor de su madre y otro Alejandría porque le gustaba el nombre de la ciudad. Alguien recordó que existía una llamada rosa de Alejandría y ya está el nombre. A veces los resultados más obvios traducen la misteriosa lógica del azar (Vázquez Montalbán 1984: 157).
\end{abstract}

En las páginas sucesivas Tourón lleva a cabo una larga reflexión sobre el nombre del barco, explicando a sus marineros la existencia, los orígenes y la localización de la rosa de Alejandría, también conocida como rosa de Damasco, así como la existencia de una canción popular española que narraba los cambios cromáticos de la flor según el momento del día. Por un lado, Vázquez Montalbán se sirve del nombre de la canción popular para nombrar al barco donde viaja el asesino, pero, por lo que él mismo escribe, en este caso concreto no guarda mucha relación con el contenido de la canción. Por otro, el capitán Tourón menciona brevemente la existencia de una canción con el nombre de la rosa, pero ello no hace que la letra cumpla alguna función dentro de la trama. No será hasta la resolución del caso, cuando el autodidacta y cliente de Carvalho, Narcís Pons Puig, describe al detective la escena del crimen, que él presenció, cuando el lector descubre el verdadero significado de la canción en la novela: Ginés, despechado, asesina a Encarna y abandona su cuerpo en la casa de los padres de Narcís, pero un personaje entra en escena, roba el cuerpo y, por lo que se deduce, es él quien lo descuartiza y lo entierra 
por partes; el autodidacta describe a este personaje como "un travesti disfrazado de señora de cincuenta años que quiere disimular que los tiene" (Vázquez Montalbán 1984: 226). Curiosamente, durante su travesía dentro de La Rosa de Alejandría, Ginés y sus compañeros descubren la afición de su capitán a vestirse de mujer y cantar coplas encerrado en su camarote; además, por las conversaciones que Tourón tiene con Ginés, se intuye que el capitán está enamorado del marino. Por tanto, la otra rosa de Alejandría de la novela es el capitán Tourón, mujer de noche, marinero de día, o, como la rosa, "colorada de noche, blanca de día". Al contrario que en Tatuaje, Carvalho no consigue dar con este dato y descubrir, gracias a la letra de la canción y a una azarosa relación, que el asesino de Encarna no fue quien descuartizo su cuerpo; el lector, pues, es el único que consigue resolver el caso por completo en La Rosa de Alejandría9. Fernández Colmeiro, por su parte, determina que la auténtica rosa de Alejandría es Encarna (2014: 158), “mujer respetablemente casada de día, pero algo putón de noche", como la recordará Carvalho veinte años después de su asesinato (Vázquez Montalbán 2006: 701), aunque ello no necesariamente excluye al capitán Tourón de la identificación simbólica, simplemente amplía el abanico significativo de la canción en la trama.

\section{A modo de conclusión}

Como ya lo hizo en su primera poesía y en su etapa experimental, Manuel Vázquez Montalbán continúa su homenaje personal a la canción de Conchita Piquer, Tatuaje, e inicia con ella la parte de su producción literaria que más fama le dará como escritor. No solo la novela toma el nombre de la conocida copla, sino que el barcelonés utiliza la historia del amor idealizado y un tanto imposible de la canción para construir el detonante y la resolución de la trama criminal resuelta por Carvalho. Podría decirse, entonces, que el detective y la canción de León, Valerio y Quiroga comparten el protagonismo en la primera novela negra montalbaniana, y que, al igual que la figura de Pepe Carvalho en Yo maté a Kennedy, lo que aparenta ser un mito o una invención se convierte en realidad en Tatuaje, en una literatura, como dice el gallego, "de carne y hueso" que lo conduce hacia el final de la trama:

Tiene la mala suerte de que el personaje me interesara. No siempre suele ocurrir. Me gusta mucho la literatura, señor Ramón. Ahora sólo me gusta la literatura de carne $y$ hueso y nuestro amigo era algo así como un héroe literario desaprovechado. Me limité, pues, a seguir las pistas encontradas y descubro a la mujer de la canción, a la auténtica mujer de la canción.

9 En la última aventura del detective, Milenio Carvalho (2004), Carvalho y Biscuter se topan casualmente con Ginés en Dakar, quien ya ha cumplido la pena carcelaria por el asesinato de Encarna y capitanea un pequeño barco bautizado de nuevo como La Rosa de Alejandría. El nuevo encuentro fugaz entre investigador e investigado sigue sin definir el verdadero papel que el capitán Tourón desempeñó en el crimen (Vázquez Montalbán 2006: 700-706).

BEOIBERÍSTICA Vol. I / Número 1 (2017) | 117-132 
-¿De qué canción?

-Eso es cosa mía (p. 240).

\section{ANEJO}

Letra de Tatuaje recogida por Manuel Vázquez Montalbán en su Cancionero general del franquismo: 1939-1975 (2000a: 8-9):

El vino en un barco

de nombre extranjero,

lo encontré en el puerto

al anochecer ${ }^{10}$

cuando el blanco faro

sobre los veleros

su beso de plata dejaba caer.

Era hermoso y rubio como la cerveza, el pecho tatuado con un corazón, en su voz amarga había la tristeza doliente y cansada del acordeón.

$\mathrm{Y}$ ante dos copas de aguardiente sobre el manchado mostrador me fue contando entre dientes" la vieja historia de su amor.

Mira mi pecho tatuado ${ }^{12}$ con este nombre de mujer, es el recuerdo del pasado que nunca más ha de volver. Ella me quiso y me ha olvidado, en cambio yo no la olvidé y para siempre voy marcado con este nombre de mujer.

Él se fue una tarde con rumbo ignorado

10 Si se escucha la canción interpretada por Conchita Piquer, se pueden apreciar algunas variantes en el texto, como en el caso de este verso: "Un anochecer".

11 "Él fue contándome entre dientes".

12 "Mira mi brazo tatuado". 
en el mismo barco

que le trajo aquí, ${ }^{13}$

pero entre mis labios

se dejó olvidado

un beso de amante

que yo le pedí.

Errante lo busco por todos los puertos,

a los marineros pregunto por él

si está vivo o muerto ${ }^{14}$

y sigo en mi duda buscándolo fiel.

$Y$ voy sangrando lentamente

de mostrador en mostrador

ante una copa de aguardiente

donde se ahoga mi dolor.

Mira su nombre tatuado ${ }^{15}$

en la caricia de mi piel,

a fuego lento lo he marcado

y para siempre iré con él.

Quizá ya tú me has olvidado,

en cambio yo no te olvidé

y hasta que no te haya encontrado

sin descansar te buscaré.

Escúchame marinero y dime:

¿qué sabes de él?

Era gallardo y altanero

y era más rubio que la miel.

Mira su nombre de extranjero

escrito aquí sobre mi piel,

si te lo encuentras marinero

dile que yo muero por él.

\footnotetext{
13 "Que lo trajo a mín.

14 "Y nadie me dice si está vivo o muerto".

15 "Mira tu nombre tatuado".
} 


\section{BIBLIOGRAFÍA}

Balibrea Enríquez, María Paz. "Tatuaje de materialismo y sexismo: Manuel Vázquez Montalbán en busca de una voz narrativa”. Anales de la Literatura Española Contemporánea, 23, 1-2 (1998): 565-584. Impreso.

Christie, Agatha. Tres ratones ciegos y otros relatos. Alberto Coscarelli (trad.). Barcelona: RBA Libros, 2014. Impreso.

Cruz Casado, Antonio. "Cancionero general: textos, pretextos y contextos." José Manuel López de Abiada et al. (eds.), Manuel Vázquez Montalbán desde la memoria. Ensayos sobre su obra, Madrid: Editorial Verbum, 2010: 126-140. Impreso.

Fernández Colmeiro, José. "Desde el balneario. Entrevista con Manuel Vázquez Montalbán". El Viejo Topo, 187 (2003): 56-67. Impreso.

- Memoria histórica e identidad cultural: de la postguerra a la postmodernidad. Rubí (Barcelona): Anthropos Editorial, 2005. Impreso.

-. El ruido y la furia. Conversaciones con Manuel Vázquez Montalbán, desde el planeta de los simios. Madrid: Iberoamericana / Frankfurt am Main: Vervuert, 2013. Impreso.

-. Crónica general del desencanto. Vázquez Montalbán - Historia y ficción. Barcelona: Anthropos Editorial, 2014. Impreso.

García García, Sergio. "Las canciones de Conchita Piquer y otras alusiones subculturales en la primera poesía de Manuel Vázquez Montalbán”. Cuadernos de Aleph, 8 (2016): 56-71. Web.

Malverde, Héctor. Guía de la novela negra. Madrid: Errata Naturae, 2010. Impreso.

Martínez Fernández, José Enrique. La intertextualidad literaria. Madrid: Cátedra, Crítica y Estudios Literarios, 2001. Impreso.

Stenzel, Hartmut. “Manuel Vázquez Montalbán. Las novelas policíacas. Pepe Carvalho en busca de la identidad de la España postfranquistam. Dieter Ingenschay y Hans-Jörg Neuschäfer (eds.), Abriendo caminos. La literatura española desde 1975, Barcelona: Lumen, Palabra Crítica, 1994: 255-267. Impreso.

Tyras, Georges. Geometrías de la memoria. Conversaciones con Manuel Vázquez Montalbán. Granada: Zoela, 2003. Impreso.

-. "Entre memoria y deseo: la poética de la huida en la obra de Vázquez Montalbán”. José Fernández Colmeiro (coord.), Manuel Vázquez Montalbán: el compromiso con la memoria, Woodbrige: Tamesis Books, 2007: 105-116. Impreso.

Vázquez Montalbán, Manuel. La Rosa de Alejandría. Barcelona: Planeta, 1984. Impreso.

—. Tatuaje. Barcelona: Plaza \& Janés, 1985. Impreso.

-. Historias de política y ficción. Barcelona: Planeta, 1989. Impreso.

—. Tres historias de amor. Barcelona: Planeta, 1990. Impreso.

—. El hermano pequeño. Barcelona: Planeta, 1994. Impreso.

-. Cancionero general del franquismo: 1939-1975. Barcelona: Crítica, 2000a. Impreso. 
—. Memoria y deseo. Obra poética (1963-1990). Barcelona: Mondadori, 2000b. Impreso.

—. Crónica sentimental de España. Barcelona: Debolsillo, 2003. Impreso.

-. Escritos subnormales. Barcelona: Debolsillo, 2005. Impreso.

-. Milenio Carvalho. Barcelona: Planeta, Booket, 2006. Impreso.

Yang, Chung-Ying. "En busca del desencanto: el caso de las primeras novelas policíacas de Manuel Vázquez Montalbán”. Letras Peninsulares, 18, 2-3 (2005-2006): 425-433. Impreso.

Fecha de recepción: 12 de enero de 2017. Fecha de aceptación: 11 de marzo de 2017. 